\title{
Membrane Material-Based Rigid Solar Array Design and Thermal Simulation for Stratospheric Airships
}

\author{
Kangwen Sun, Ming Zhu, and Qiang Liu \\ School of Aeronautic Science and Technology, Beihang University, Beijing 100191, China \\ Correspondence should be addressed to Kangwen Sun; sunkw100@buaa.edu.cn
}

Received 3 April 2014; Revised 29 June 2014; Accepted 1 July 2014; Published 19 August 2014

Academic Editor: Ying Li

Copyright (c) 2014 Kangwen Sun et al. This is an open access article distributed under the Creative Commons Attribution License, which permits unrestricted use, distribution, and reproduction in any medium, provided the original work is properly cited.

\begin{abstract}
In order to improve effective utilization of rigid solar array used in stratospheric airships here, the flexible connection design and light laminated design were introduced to rigid solar array. Based on the analysis of the design scheme, firstly, the equivalent coefficient of thermal conductivity was calculated by the theoretical formula. Subsequently, the temperature variation characteristics of the solar cell module were accurately modeled and simulated by using Computational Fluid Dynamics (CFD) software. Compared to the results of test samples, the solar cell module described here guaranteed effective output as well as good heat insulating ability, effectively improving the feasibility of the stratospheric airship design. In addition, the simulation model can effectively simulate the temperature variation characteristics of the solar cell, which, therefore, provides technical support for the engineering application.
\end{abstract}

\section{Introduction}

The advantages of stratospheric airships include long endurance, wide-area coverage, strong-survival ability, and low cost of manufacture and maintenance. As a highaltitude platform, stratospheric airships have wide military and civilian applications, especially in communication relay, remote sensing, high-resolution earth observation, environmental monitoring, and so on, which has become a hot research field around the world [1-3].

In 2003, NASA carried out a feasibility research on the stratospheric airship and the efficient solar array, advanced energy storage and management system, novel high-altitude propeller and electric propulsion system, and lightweight high-strength envelop materials were defined as the four key technologies of the stratospheric airship [4].

At present, the analysis on energy system has been relatively perfected, especially on the electrical characteristics of the solar array [5-8], but the analysis on the thermal characteristics of the solar array was relatively few $[9,10]$, and the effective control methods of the thermal characteristics of it were fewer reported than above. However, in the conventional design scheme, solar array mounts on the surface of the stratospheric airship; then, the temperature difference between solar cell surface and envelop surface, where no solar array overcasts, could go up to $60^{\circ} \mathrm{C}$ in the daytime, which is discussed by Xia et al. [9], because the conversion efficiency of thin film flexible solar array was very low $(10 \sim 12 \%)$. Therefore, the conversion efficiency of the solar cell must be enhanced, and the imperative heat insulation measures between solar cells and the airship envelop must be taken.

As for the problems mentioned above, this paper will focus on rigid solar cell, whose conversion efficiency can reach up to $20 \%$ and even higher, and effective utilization in the stratospheric airship with rigid-flexible design method. Furthermore, as support structure to rigid solar cell, the honeycomb sandwich structure can also obtain effective insulation. In this paper, the temperature variation characteristics of solar cell module were accurately simulated and analyzed by Computational Fluid Dynamics (CFD) software followed by the verification of the rationality of the design, as well as the validity of the simulation model.

\section{Flexible Processing of Rigid Solar Cell}

American researchers have studied the application of rigid solar cell in the stratospheric aerostats, and the implementation scheme adopted hanging method to mount solar array 


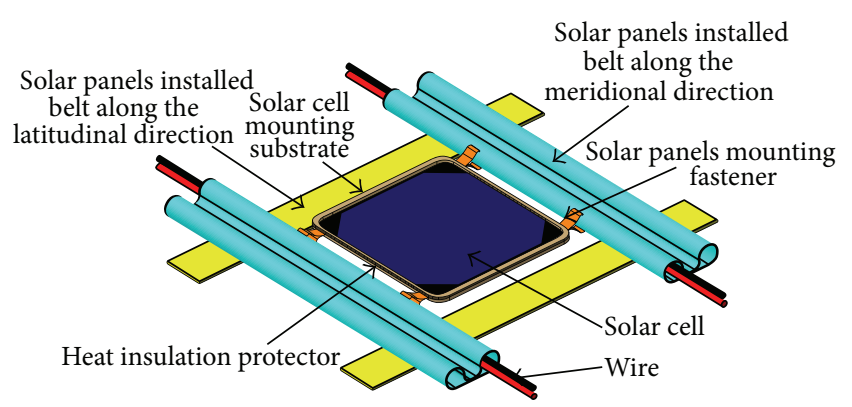

Figure 1: "Fish scale" design scheme for rigid solar cell module (single piece as shown).

on the buoyancy body in the form of modules [11, 12]. Due to the solar array irresponsibility in the drive mechanism and the big scale existing in the whole structure in the height direction, this leads to the failure of the application of design plans.

To deal with the big global scale and small local curvature of stratospheric airship, this paper proposed a "fish scale" shape design for the flexible application of rigid solar cell. One or more pieces of efficient solar cell were lightweighthard packaged to form modules (module size was designed according to airship curvature), and then they were mounted on the soft net laminated with soft fabric woven, and finally the series parallel cables between rigid solar cell and the final main transmission cables were laid in the pipeline above the soft net (as shown in Figure 1). The above design scheme can ensure high-efficiency output of solar array as much as possible; meanwhile, it realizes the effective application of rigid cell array in the stratospheric airship. In addition, the reasonable application of monolayer board honeycomb sandwich structure can achieve rigid support and effective heat insulation for the rigid solar cell. The solar array design based on the above idea is shown in Figure 2.

\section{Analysis of Equivalent Thermal Conductivity}

The stratospheric solar cell module discussed in this paper uses a multilayer film and Nomex honeycomb sandwich structure to meet the requirement of lightweight design. And its composition and basic characteristics of each layer are shown in Table 1 . The areal density of this module can achieve the lighter density at $1.7 \sim 2.0 \mathrm{~kg} / \mathrm{m}^{2}$ which is lower than that of solar cell module at $2.25 \mathrm{~kg} / \mathrm{m}^{2}$ (tensile membrane semirigid structure, given by Guoxin [13]).

According to Table 1, in order to determine the temperature characteristics of the upper and lower surface of the above solar cell module, parameter analysis is shown as follows.

The upper of solar cell module consists of 5-layer materials that are tightly compressed together, and the overall thermal resistance $R_{\text {upper }}$ can be expressed as

$$
R_{\text {upper }}=\frac{\delta_{1}}{\lambda_{1}}+\frac{\delta_{2}}{\lambda_{2}}+\frac{\delta_{3}}{\lambda_{3}}+\frac{\delta_{4}}{\lambda_{4}}+\frac{\delta_{5}}{\lambda_{5}} .
$$

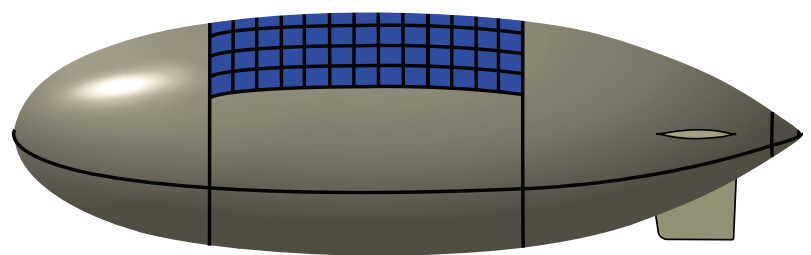

Figure 2: "Fish scale" design scheme for rigid solar array on stratospheric airship.

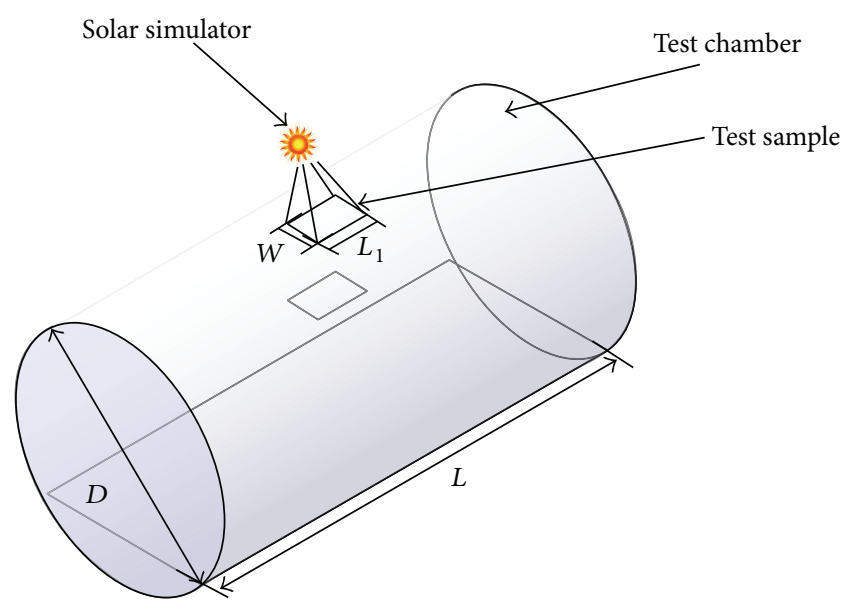

FIGURE 3: Test chamber and test specimen.

$\delta_{\text {upper }}$ denotes the total thickness of the upper:

$$
\delta_{\text {upper }}=\delta_{1}+\delta_{2}+\delta_{3}+\delta_{4}+\delta_{5}
$$

$\lambda_{\text {upper }}$ denotes the equivalent thermal conductivity of the upper:

$$
\lambda_{\text {upper }}=\frac{\delta_{\text {upper }}}{R_{\text {upper }}} .
$$

After calculation, $\delta_{\text {upper }}=0.77 \times 10^{-3} \mathrm{~m} ; \lambda_{\text {upper }}=0.256 \mathrm{~W} / \mathrm{m}$. K.

According to Figure 3 and Table 1, the lower part of the solar cell module is made up of two monolayer carbon fiberboards which are tightly laminated on $10 \mathrm{~mm}$ honeycomb sandwich formed by both top and bottom of Nomex honeycomb. Heat conducts from the surface to the upper monolayer carbon fiberboard through 5-layer materials, and then through honeycomb it conducts to the bottom of the monolayer carbon fiberboard. Finally, the monolayer carbon fiberboard transfers heat into the environment through thermal radiation and heat convection. In order to build a calculation model of equivalent thermal conductivity coefficient, it is necessary to inspect honeycomb cell unit.

The specification of the honeycomb core used in solar cell module is described as follows: side length $l=1.83 \times$ $10^{-3} \mathrm{~m}$, height $H=1.0 \times 10^{-2} \mathrm{~m}$, and thickness of monolayer wall $t=0.125 \times 10^{-3} \mathrm{~m}$. Within the cavity formed by this core, air convection heat transfer within honeycomb can be ignored because of relative seal of the space. Based on 
TABLE 1: Materials physical parameters of lightweight and high-efficiency solar cell module.

\begin{tabular}{|c|c|c|c|c|c|}
\hline Number & Material & Thickness $\delta\left(10^{-3} \mathrm{~m}\right)$ & Thermal conductivity $\lambda(\mathrm{W} / \mathrm{m} \cdot \mathrm{K})$ & Emissivity & Light transmittance \\
\hline 1 & Surface packaging film & 0.12 & 0.22 & 0.92 & $92 \%$ \\
\hline 2 & Transparency adhesive film & 0.3 & 0.32 & - & $91 \%$ \\
\hline 3 & Si solar cell & 0.2 & 0.21 & - & - \\
\hline 4 & Lightweight adhesive film & 0.1 & 0.6 & - & - \\
\hline 5 & Electric insulation film & 0.05 & 0.12 & - & - \\
\hline 6 & Monolayer carbon fiberboard & 0.125 & 0.78 & - & - \\
\hline 7 & Nomex honeycomb core & 10 & 0.17 & 0.94 & - \\
\hline 8 & Monolayer carbon fiberboard & 0.125 & 0.78 & 0.98 & - \\
\hline
\end{tabular}

the above analysis, the heat transfer model of honeycomb sandwich structure includes solid heat conduction inside the cell wall of sandwich layer, air heat conduction inside honeycomb, and radiation heat transfer between the topbottom panel and honeycomb cell wall. With reference to the above three kinds of heat transfer mechanism, the effective thermal conductivity $\lambda_{7}$ of honeycomb sandwich structure can be expressed as follows:

$$
\lambda_{7}=\lambda_{f} \frac{\Delta A}{A}+\lambda_{a}\left(1-\frac{\Delta A}{A}\right)+\lambda_{r}
$$

where $\lambda_{f}$ is the thermal conductivity coefficient of honeycomb matrix material, $\lambda_{a}$ is the thermal conductivity coefficient of air within the sandwich structure, $\lambda_{r}$ is the radiation thermal conductivity coefficient between the topbottom board and honeycomb cell wall, $\Delta A=16 l \Delta t$ is the cross-sectional area of the material, and $A=6 \sqrt{3} l^{2}$ is the cross-sectional area of cell unit.

The air thermal conductivity coefficient within honeycomb sandwich structure is formulated as follows:

$$
\lambda_{a}=0.0241 \cdot\left(\frac{T_{a}}{273.15}\right)^{0.9},
$$

where $T_{a}$ is the characteristic temperature of air thermal conductivity coefficient, while $T_{1}$ and $T_{2}$ are the top and bottom temperature, respectively:

$$
T_{a}=\frac{T_{1}+T_{2}}{2}
$$

The calculation formula of equivalent radiation thermal conductivity is shown as follows (given by Swann Robert and Pittman Claud [14]):

$$
\begin{aligned}
\lambda_{r}= & 0.664 \times(\eta+0.3)^{-0.69} \\
& \times H \times \varepsilon^{1.63(\eta+1)^{-0.89}} \times \sigma \\
& \times\left(T_{1}+T_{2}\right) \times\left(T_{1}^{2}+T_{2}^{2}\right) .
\end{aligned}
$$

$\eta=H / l$ is the ratio of honeycomb height to its cell size; $\varepsilon$ is the radiation rate of internal honeycomb structure; and $\sigma=5.67 \times 10^{-8} \mathrm{~W} / \mathrm{m}^{2} \cdot \mathrm{K}^{4}$ is the Stefan-Boltzmann blackbody radiation constant.

$T_{1}$ and $T_{2}$ are unknown, and they need to be determined by the iterative calculation. The experimental measurement value (according to the test data, $T_{1}=345 \mathrm{~K}, T_{2}=315 \mathrm{~K}$ are defined in this paper) is substituted into the formula, and the surface temperature of solar cell module is iteratively calculated after the thermal conductivity coefficient of the air and the equivalent thermal conductivity coefficient of the honeycomb are calculated.

The thermal resistance of the lower solar cell module is expressed as $R_{\text {lower }}$, and its expression is described as follows:

$$
R_{\text {lower }}=\frac{\delta_{6}}{\lambda_{6}}+\frac{\delta_{7}}{\lambda_{7}}+\frac{\delta_{8}}{\lambda_{8}} .
$$

$\delta_{\text {lower }}$ denotes the total thickness of the lower part and its expression is shown as follows:

$$
\delta_{\text {lower }}=\delta_{6}+\delta_{7}+\delta_{8} .
$$

$\lambda_{\text {lower }}$ denotes the equivalent thermal conductivity coefficient of the lower part and its expression is shown as follows:

$$
\lambda_{\text {lower }}=\frac{\delta_{\text {lower }}}{R_{\text {lower }}} .
$$

Consequently, $\delta_{\text {lower }}=1.025 \times 10^{-2} \mathrm{~m} ; \lambda_{\text {lower }}=0.131 \mathrm{~W} / \mathrm{m} \cdot \mathrm{K}$.

\section{Experimental Measurements}

The dimension of environmental test chamber was $D \times L=$ $\Phi 1.8 \mathrm{~m} \times 3.5 \mathrm{~m}$ and the solar simulator was installed in the middle so as to simulate the radiation from the sun, whereas the dimension of the test specimen was $L_{1} \times W \times H=$ $0.42 \mathrm{~m} \times 0.27 \mathrm{~m} \times 0.0065 \mathrm{~m}$ (which can be seen from Figure 3). Then, the specimen beneath the solar simulator was put in the environmental test chamber and the distance between the specimen and the top of the chamber was $H_{1}=0.59 \mathrm{~m}$, whereas the distance between the specimen and the bottom of the chamber was $H_{2}=0.93 \mathrm{~m}$. And the remaining length $\mathrm{H}_{2}=0.28$ is the height of the bracket (i.e., $\mathrm{H}_{1}+\mathrm{H}_{2}+\mathrm{H}_{3}+=\mathrm{D}$ ).

The test ambient pressure was 5000 pa (20 km altitude), and the ambient temperature of test site was $12^{\circ} \mathrm{C}$. At the same time, according to the calculation model of solar radiation, which is discussed by Lacis and Hansen [15], the solar vertical radiation reference intensity in stratosphere can be set at $1260 \mathrm{~W} / \mathrm{m}^{2}$. When the chamber reached a steady state, the temperature of chamber wall and the temperature of internal chamber air were $15^{\circ} \mathrm{C}$ (assume for December 22 in this 
TABLE 2: Temperature test data of test specimens.

\begin{tabular}{|c|c|c|c|c|c|c|}
\hline & $\operatorname{TMP} 1\left({ }^{\circ} \mathrm{C}\right)$ & TMP $2\left({ }^{\circ} \mathrm{C}\right)$ & TMP $3\left({ }^{\circ} \mathrm{C}\right)$ & TMP $4\left({ }^{\circ} \mathrm{C}\right)$ & TMP $5\left({ }^{\circ} \mathrm{C}\right)$ & $\operatorname{TMP} 6\left({ }^{\circ} \mathrm{C}\right)$ \\
\hline Group 1 & 68.3 & 70.5 & 68.9 & 40.2 & 43.5 & 41.3 \\
\hline Group 2 & 70.5 & 70.4 & 68.5 & 39.5 & 43.6 & 40.5 \\
\hline Group 3 & 71.2 & 70.9 & 68.3 & 42.1 & 42.6 & 39.2 \\
\hline Group 4 & 72.9 & 71.7 & 69.9 & 40.5 & 43.4 & 40.7 \\
\hline Group 5 & 72.6 & 71.4 & 69.4 & 40.7 & 43.9 & 41.3 \\
\hline Group 6 & 73.3 & 72.1 & 69 & 42.2 & 43.7 & 41.2 \\
\hline Group 7 & 74 & 71.8 & 69.5 & 40 & 43.7 & 40.4 \\
\hline Group 8 & 72.7 & 71.4 & 68.1 & 42.7 & 44.1 & 39.6 \\
\hline Group 9 & 71.2 & 71 & 68.6 & 42.1 & 43.7 & 39 \\
\hline Average & 71.9 & 71.2 & 68.9 & 41.1 & 43.6 & 40.4 \\
\hline
\end{tabular}

TABLE 3: Test specimens' surface average temperature and temperature difference.

\begin{tabular}{lrr}
\hline Number & Parameter declaration & Value \\
\hline 1 & Standard deviation between test points on upper surface & 1.64 \\
2 & Standard deviation between test points on lower surface & 1.61 \\
3 & The average temperature of upper surface & $70.67^{\circ} \mathrm{C}(343.82 \mathrm{~K})$ \\
4 & The average temperature of lower surface & $41.68^{\circ} \mathrm{C}(314.83 \mathrm{~K})$ \\
5 & The temperature difference between upper surface and lower surface & $28.99^{\circ} \mathrm{C}(28.99 \mathrm{~K})$ \\
\hline
\end{tabular}

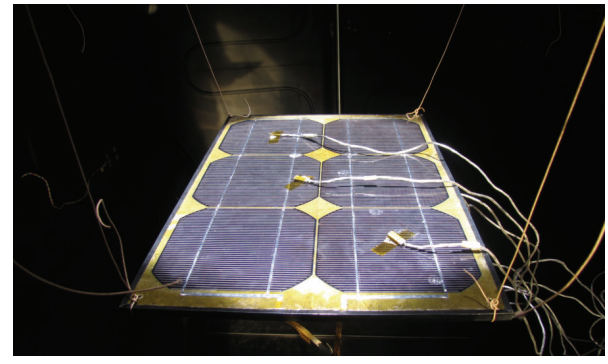

FIGURE 4: Test specimen temperature test.

paper) [16], due to the radiation heating effect of the solar simulator. Test image was shown in Figure 4.

The locations of temperature measuring point are shown in Figure 5. There are three temperature measuring points on the upper surface of the solar cell module, where the temperature measuring point (TMP) 4 is on the back of the TMP 1, the TMP 5 is on the back of the TMP 2, and the TMP 6 is on the back of the TMP 3 .

At room temperature, the infrared thermometer was used to measure the temperature on the surface of the specimen and 9 groups of data were obtained and listed in Table 2; at the same time, the average temperature of specimen surface and the data of the temperature difference are shown in Table 3.

For Tables 2 and 3, there are two points that need to be made as follows.

(1) The temperature difference for the same side point was mainly due to the inhomogeneity of the solar simulator light intensity in a certain scale.

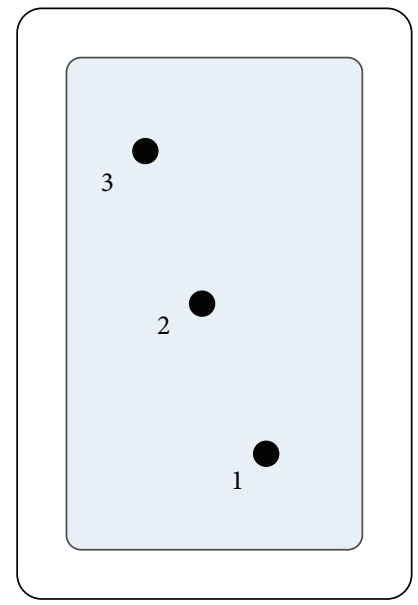

Positive

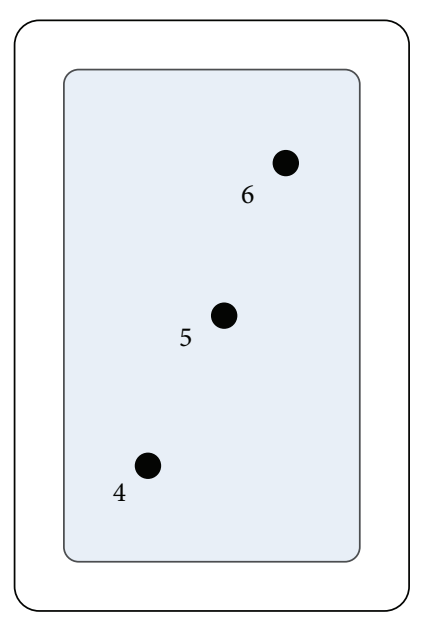

Back
FIGURE 5: Schematic diagram of test specimen surface TMPs arrangement.

(2) The standard deviation of the test points in the same side is about 1.6 , less than the final temperature difference value of $1.65 \%$, whose effect on the analysis results is very small. Then, it is belongs to the range of acceptable.

\section{Simulation Calculations}

5.1. Modeling and Setting Up of Boundary Conditions. According to the test equipment dimension, a threedimensional model for temperature calculation of solar cell 

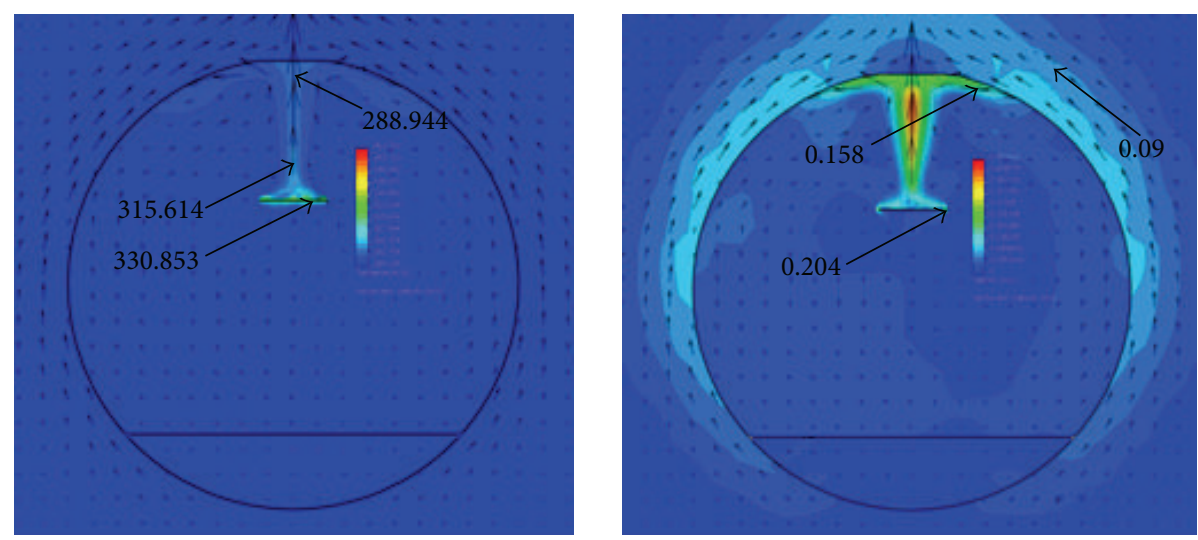

Figure 6: Cross-section temperature and velocity field of the test specimen.
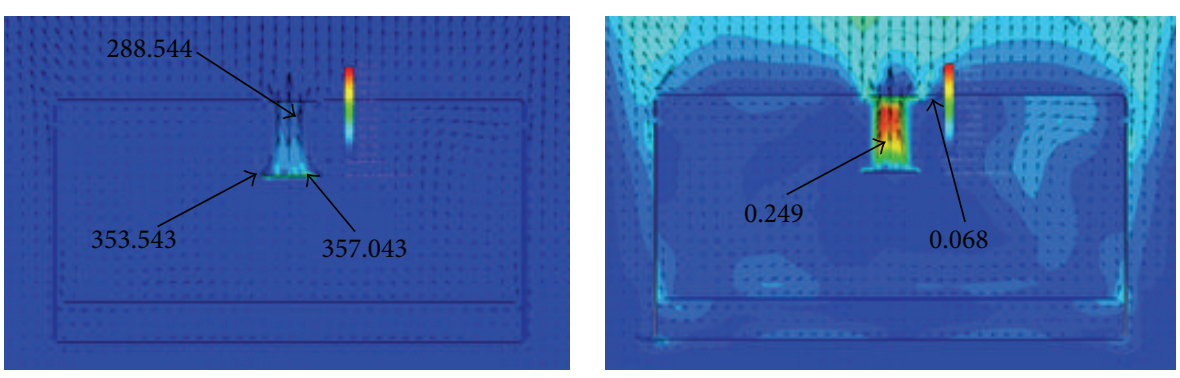

FIGURE 7: Longitudinal section temperature and velocity field of the test specimen.

module was built, and test specimen was set up in the middle of environmental test chamber and below the solar simulator.

The inwall thickness of test chamber was $4 \mathrm{~mm}$, and the surface emissivity and absorptivity were 0.98 after roughness of copper because the copper could guarantee the temperature of environmental chamber being uniform. Therefore, the inwall emissivity and absorptivity of ambient chamber model were set as 0.98 , and the temperature of the chamber wall was set as $15^{\circ} \mathrm{C}$, which could guarantee the internal ambient temperature of simulation module being stable at $15^{\circ} \mathrm{C}$. The radiation intensity of solar simulator was $1260 \mathrm{~W} / \mathrm{m}^{2}$.

The radiation characteristics of the specimen upper surface are directly related to the radiation properties of surface encapsulating film and transparency adhesive film, and the light transmittance of the surface encapsulating film and the transparency adhesive film are 0.92 and 0.91 , respectively. Thus, the absorption rate of the sunlight on the upper surface of the specimen is set as 0.8372 , and the emissivity of the surface encapsulating film is 0.92 , so the emissivity of specimen upper surface is set as 0.92 . The absorption rate of the specimen lower surface is set as 0.94 , and the emissivity is set as 0.98 .

When calculating the temperature field and flow field, the approach of local grid refinement is applied in the calculation because the smallest thickness is the upper part of the solar cell module $(0.77 \mathrm{~mm})$. The solid grid minimum size of the specimen is set as $0.5 \mathrm{~mm}$ to ensure that the upper part of the solar cell module can fully participate in heat transfer calculation. 385900 grids are generated from the calculation, and the temperature field and the velocity field of test chamber; the temperature field of the specimen surface can be obtained accurately after calculation in $100 \mathrm{~min}$.

5.2. Results of Simulation Calculation. The distribution of the temperature field and velocity field outside the test chamber are shown in Figures 6 and 7, and obviously the wall temperature of the test chamber is higher than the ambient temperature. Therefore, the air outside the test chamber rises up along the wall of the test chamber, and the air temperature close to the surface goes up higher and higher due to frictional heating. Meanwhile, the difference between this air temperature and ambient temperature is getting bigger and bigger. Therefore, the rising velocity of air close to the wall is getting bigger and bigger.

In the test chamber, the temperature of the specimen went up due to solar radiation effect, which simultaneously heated the surrounding air. The heated air flowed up under the drive of buoyancy, and it went along the wall of the test chamber by the drive of hot air after it reached the top. The hot air was cooled and flowed down along the wall of the test chamber because the temperature of hot air was higher than that of the wall of the test chamber. Therefore, the air within the test chamber was heated by the specimen, forming two circles by the buoyancy.

Figure 8 was the distribution of the specimen surface temperature, and the labels in figure were corresponding to the temperature data in the measuring point. 

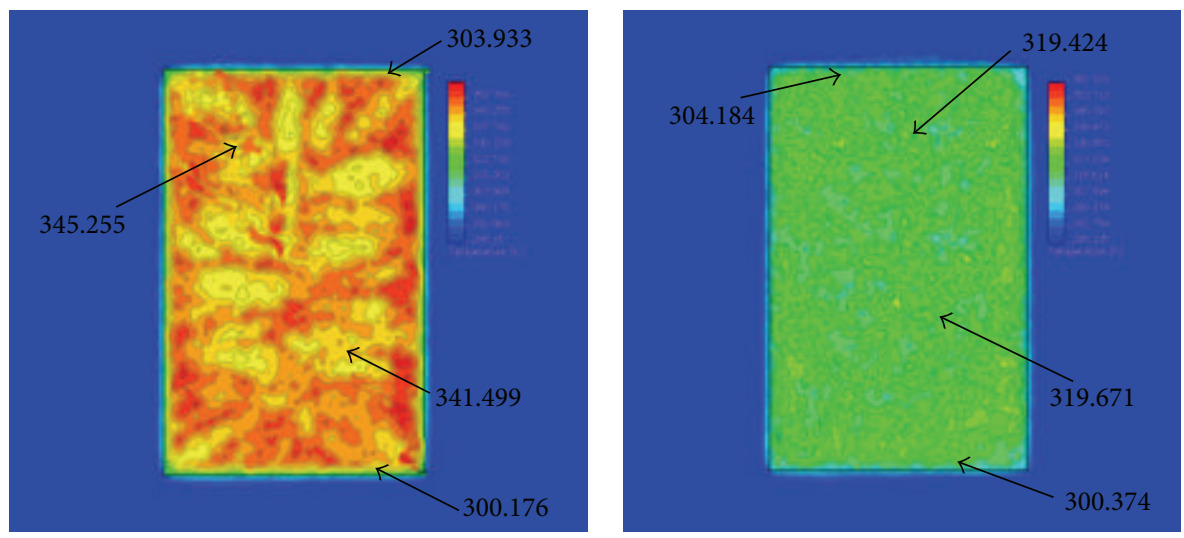

FIGURE 8: The temperature distribution of test specimen upper surface and lower surface.

TABLE 4: Data of experiment and simulation comparison table.

\begin{tabular}{|c|c|c|c|}
\hline & Experimentation & Simulation & Error \\
\hline Upper surface temperature & $343.82 \mathrm{~K}$ & $346.2 \mathrm{~K}$ & $0.7 \%$ \\
\hline Lower surface temperature & $314.83 \mathrm{~K}$ & $320.5 \mathrm{~K}$ & $1.8 \%$ \\
\hline The temperature difference between upper surface and lower surface & $28.99 \mathrm{~K}$ & $25.7 \mathrm{~K}$ & $11.3 \%$ \\
\hline
\end{tabular}

Comparing the simulation results and test results (as shown in Table 4), there is little relative error between them, which indicated that the simulation model built here is effective for the thermal characteristics analysis of lightweight and high-efficiency solar cell module. Data comparison shows that the relative error on the absolute value of the upper and lower surface temperatures that were obtained by measurement and calculation is less than $2 \%$, and the relative error of the temperature difference is less than $12 \%$, which can completely satisfy the requirement of the early stage design precision; thus it can be applied to the analysis of the related design reference.

\section{Conclusions}

Taken together, in consideration of the low conversion efficiency of thin film solar cell used in the stratospheric airship and the lack of the thermal control measures between the capsule body and the cell, rigid solar cell modules are flexibly connected and secured to the stratospheric airship with the method of rigid-flexible integration design which can ensure that solar arrays incorporate into the airship surface properly. Meanwhile, the honeycomb sandwich structure used in space solar array is applied to this scheme. Based on the characteristics of the stratospheric environment, membranepackaged materials are used to largely reduce the surface density of solar arrays. On the basis of component analysis of the design scheme, theoretical formula is employed to calculate the equivalent thermal conductivity coefficient of this structure. Subsequently, the CFD software is applied to accurately model and analyze the temperature variation characteristics of the solar cell module. The comparative analysis of the experimental data and simulation results shows that the application solutions for the solar cell module proposed in this paper can insulate heat effectively between the solar array and the airship envelop; meanwhile it can reduce the covering area for the solar array mounted on the airship as much as possible. In addition, the simulation model built in this paper can effectively simulate the temperature variation characteristics of the solar cell, which provides further technical supports for the engineering application.

\section{Conflict of Interests}

The authors declare that they do not have any commercial or associative interest that represents a conflict of interests in connection with the work submitted.

\section{Acknowledgments}

This work was supported by the National Natural Science Foundation of China under Grant no. 51307004 and Shanghai Aerospace Science and Technology Innovation Fund no. SAST201268.

\section{References}

[1] P. Hendrick, L. Hallet, and D. Verstraete, "Comparison of propulsion technologies for a HALE airship," in Proceedings of the 7th AIAA Aviation Technology, Integration, and Operations Conference (ATIO '07), pp. 527-534, Belfast, UK, September 2007.

[2] A. J. Knoedler, "Lowering the high ground: using near-space vehicles for persistent ISR," Military Technology, vol. 32, no. 6, pp. 178-187, 2008.

[3] D. K. Schmidt, J. Stevens, and J. Roney, "Near-space stationkeeping performance of a large high-altitude notional airship," Journal of Aircraft, vol. 44, no. 2, pp. 611-615, 2007. 
[4] Anthony Colozza (Analex Corporation, Brook Park, Ohio, USA), Initial Feasibility Assessment of a High Altitude LongEndurance Airship. Glenn Research Center, National Aeronautics and Space Administration. Report no.: NASA/CR-2003212724. Contract no.: NAS3-00145, 2003.

[5] J. B. Mueller, Y. J. Zhao, and W. L. Garrardz, "Sensitivity and solar power analysis of optimal trajectories for autonomous airships," in Proceedings of the AIAA Guidance, Navigation, and Control Conference, AIAA, Chicago, Ill, USA, August 2009.

[6] K. Sun, C. Liu, G. Liang, and M. Zhu, "Simulation analysis for solar array output characteristics on stratospheric airship," in Proceedings of the IASTED International Conference on Power and Energy Systems and Applications (PESA '12), pp. 158-162, Las Vegas, Nev, USA, November 2012.

[7] S. Okaya, N. Shinozaki, S. Sasa, T. Fujihara, and K. Harada, "R\&D status of RFC technology for SPF airship in Japan," in Proceedings of the 9th Annual International Energy Conversion Engineering Conference (IECEC '11), San Diego, Calif, USA, August 2011.

[8] A. K. Garg, S. K. Burnwal, A. Pallapothu, R. S. Alawa, and A. K. Ghosh, "Solar panel area estimation and optimization for geostationary stratospheric airships," in Proceedings of the 11th AIAA Aviation Technology, Integration, and Operations Conference (ATIO), including the AIA, Virginia Beach, Va, USA, September 2011.

[9] X. Xia, D. Li, and X. Yang, "Thermal characteristics of stratospheric aerostats and their research," Acta Aeronautica et Astronautica Sinica, vol. 30, no. 4, pp. 577-583, 2009 (Chinese).

[10] Y. W. Wang and C. X. Yang, "A comprehensive numerical model examining the thermal performance of airships," Advances in Space Research, vol. 48, no. 9, pp. 1515-1522, 2011.

[11] M. Aaron Kim, C. Barnes Nathan, R. Burger Dale, and T. Nock Kerry, "HIGHPOWER solar array system for balloons," in Proceedings of the 3th AIAA Annual Aviation Technology, Integration, and Operations (ATIO '03), Denver, Colorado, Nomaber 2003.

[12] R. Burger Dale, M. Aaron Kirn, T. Nock Kerry, K. Heun Matthew, and W. Linfield Brenda, "A lightweight modular solar array for ultra-long duration balloon (ULDB) missions," in Proceedings of the 39th A1AA Aerospace Sciences Meeting and Exhibit, Reno, Nev, USA, 2001.

[13] L. Guoxin, Spacecraft Power System Technology, China Aerospace Press, Beijing, China, 2008, (Chinese).

[14] T. Swann Robert and M. Pittman Claud, Numerical analysis of the transient response of advanced thermal protection systems for atmospheric entry, National Aeronautics and Space Administration, 1962.

[15] A. A. Lacis and J. E. Hansen, "A parameterization for the absorption of solar radiation in the earth's atmosphere," Journal of the Atmospheric Sciences, vol. 31, no. 1, pp. 118-133, 1974.

[16] Y. W. Wang and C. X. Yang, "Thermal analysis of stratopheric airship in working process," in Proceedings of the AIAA Balloon Systems Conference, Seattle, Wash, USA, May 2009. 

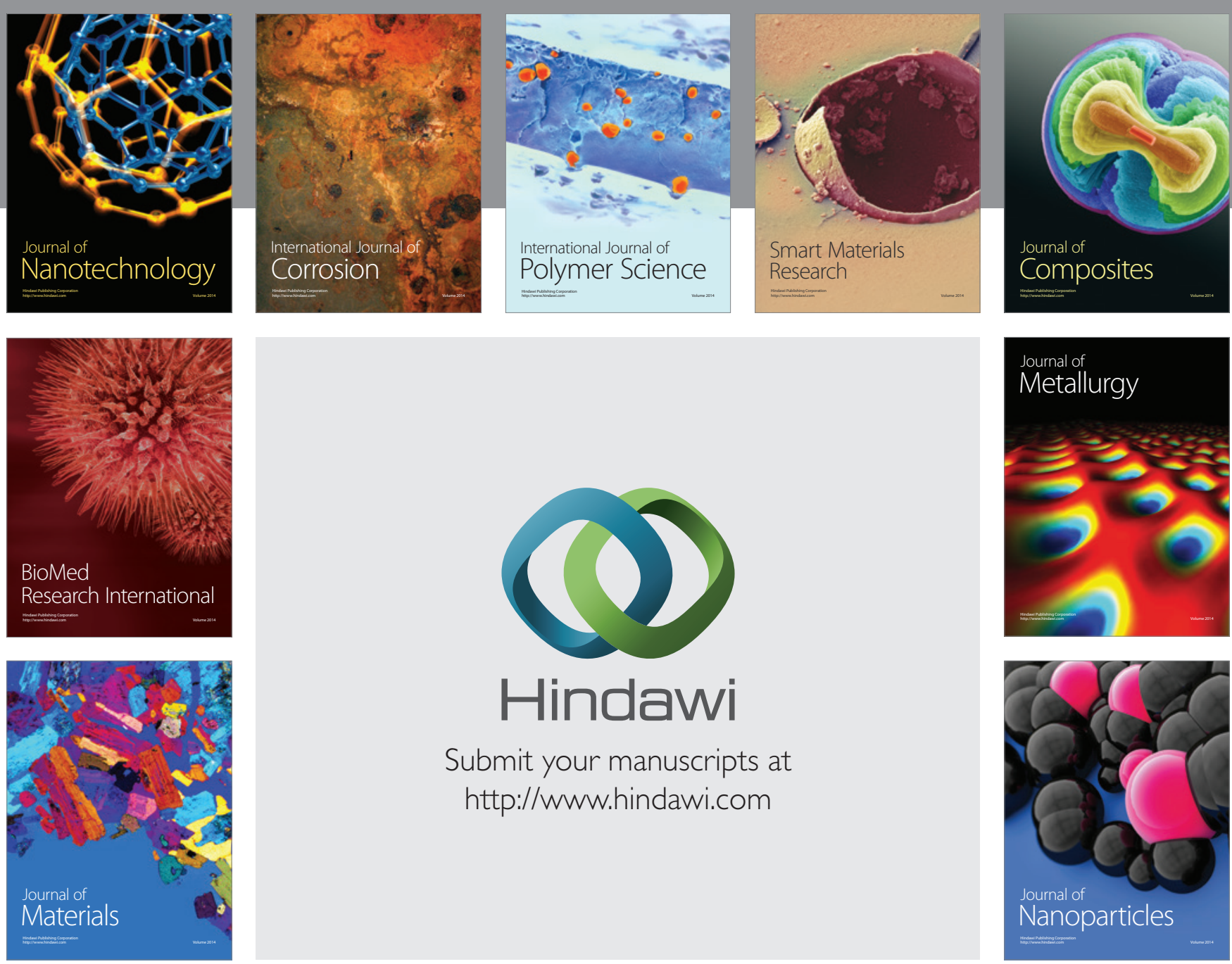

Submit your manuscripts at http://www.hindawi.com
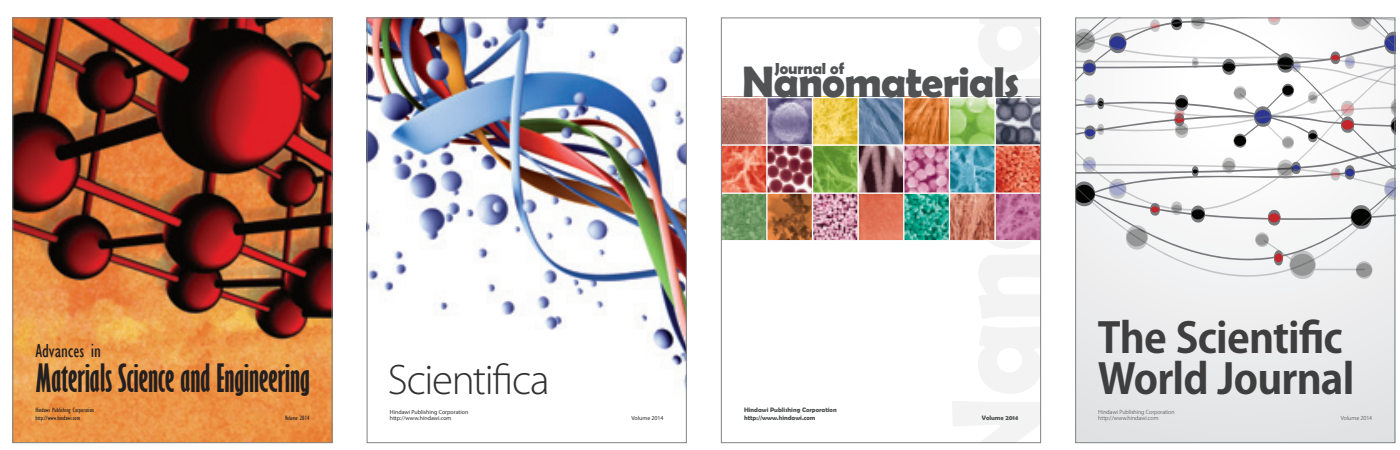

\section{The Scientific World Journal}
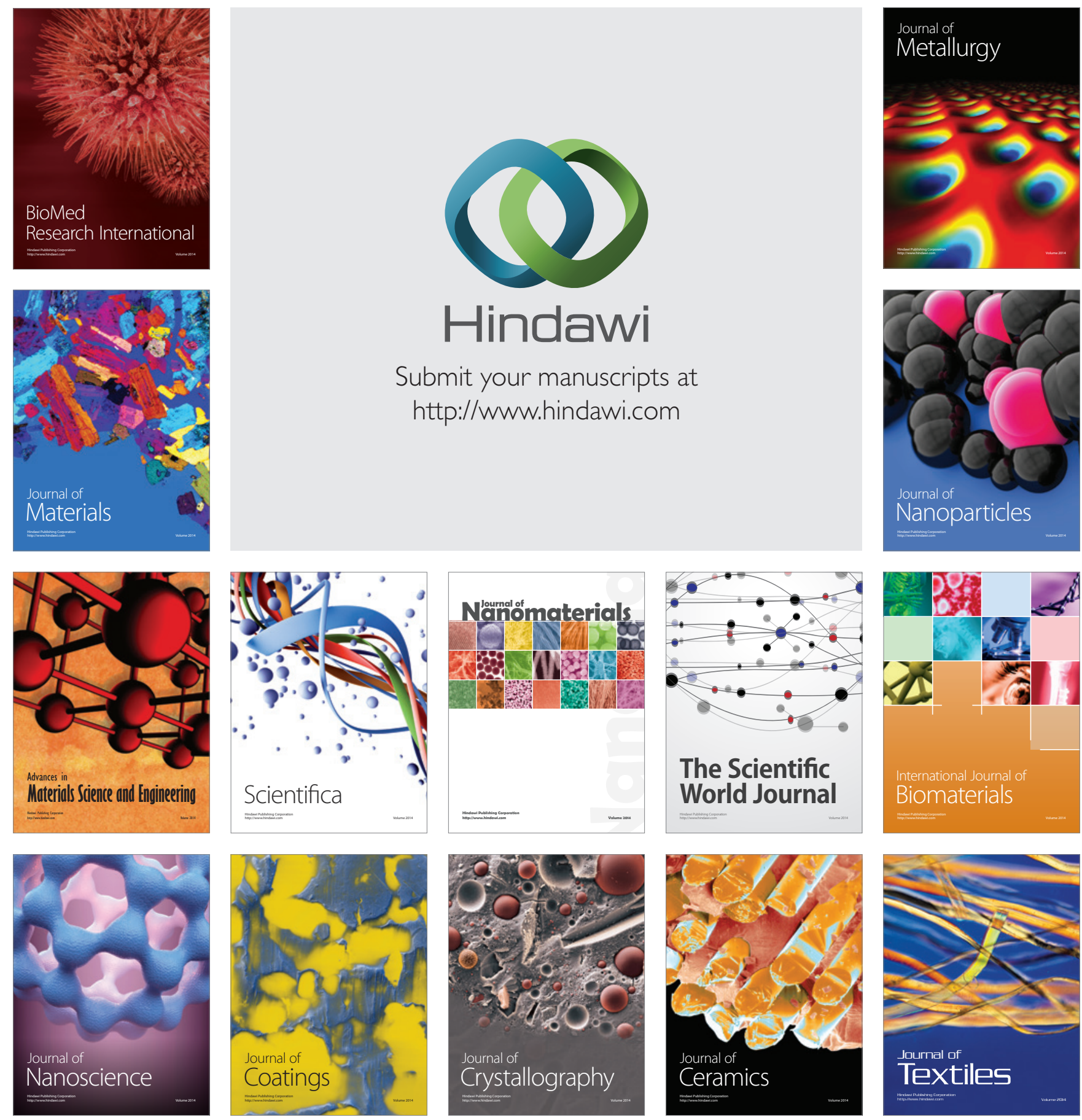